\title{
A model and process for assessing the technology infusion impact on uncertain aeronautical products
}

\author{
Henrique Abrahão Alves ${ }^{a}$, Luís Gonzaga Trabasso \\ aEmbraer S.A. \\ bInstituto Tecnológico de Aeronáutica \\ e-mails: henrique.alves@embraer.com.br; gonzaga@ita.br
}

\begin{abstract}
This paper presents a method for assessing the impact of infusing one or more technologies in aeronautical products in early design phases with their associated uncertainty. The global changes are building an aeronautical scenario which demands products with low costs, better performance, safety, quality and environmentally friendly. To achieve this demand, it is necessary to infuse technologies able to improve the product and/or processes. However, prior to that, it is necessary to bring and deal with information about the impact of technologies infusion to the early phases of the aircraft design and the uncertainty aspects of applying new technologies. This would provide a better decision making on which technologies to use. The proposed approach described herein is a response to the need for assessing and estimating the impact of technology infusion in aeronautical products under the new scenario, improving the decision making process at the aircraft design early phases. This goal is achieved through a process using approaches, techniques and tools that address product and technology perspective, such as System Engineering, Concurrent Engineering, Technology Scouting, Technological Forecasting and Probabilistic Techniques. The proposed method is applied to a theoretical case study illustrating the overall process and results that could be expected.
\end{abstract}

Keywords: technology infusion, technological forecasting, integrated product development.

\section{Introduction}

The changing global socio-economical and political environment is being a remarkable phenomenon over the last decades of XX century and the beginning of XXI century.The airline industry market deregulation started by USA by the end of the 1970's and followed by others countries, increased airlines crises after September 11th terrorism attacks, the uncertainty price of aviation fuel in a long term perspective, increase and changes in environmental regulation, the forecasting raise of world air traffic, the programs of Research, Technology and Development funding by USA and European Community: all of these together with the overcoming desire for products with better quality, comfort and safety are some of the main features that configure the world scenario and have important impact at the aeronautic market.This market, thus, demands products with low costs, better performance, safety, quality and environmentally friendly.To achieve this demand, it is necessary to infuse technologies that might improve the product and/or processes. However, prior to that, it is necessary to bring and deal with information about the impact of technologies infusion to the early phases of the aircraft design and the uncertainty aspects of applying new technologies.

In general, the impact of a technology is immersed in uncertainty by nature, due to incomplete knowledge about the system and the behavior of the system with the new technology. The concept of uncertainty is identified as a key element to deal with in a technology development or product design environment, and it is one of the reasons to employing probabilistic approaches (BAKER, 2002; MANKINS, 1995).

In a broad view, uncertainty implies that multiple outcomes or results are possible.In the context of system design, this implies that multiple system responses are possible when variability associated with design information (i.e. requirements, concepts, and technologies) is deployed to the system level, cording to Baker (2002).The uncertainty, and therefore the probabilistic nature, arises from various contributing factors, especially if the technology is not fully matured.The innovative process by which a technology is developed can be qualitatively described through a monitoring of the major milestones achieved from concept formulation to widespread application. As defined by 
NASA for application in the aerospace community, the milestones have been characterized by a metric known as the Technology Readiness Level - TRL (MANKINS, 1995). Based upon these challenges the present work aims at proposing a model and process to assess impact of infusing one or more technologies, with their uncertainties, in aeronautical product under the criteria of stakeholders needs.

\section{Enabling techniques}

In order to respond to a generic process to assessing the impact of infusion of one or more technologies in aeronautical products and the related uncertainty, enabling techniques from product, technology and probabilistic fields must be identified so as to determine possible solutions to the shortcoming of the process and approaches presented.

The techniques include Concurrent Engineering, System Engineering, Technology Assessment, Technology Forecasting, Technology Description Process and Technology Scouting, all of those addresses the product, technology or both points of view and also the Monte Carlo simulation as a probabilistic technique to address uncertainty. As these techniques are well known and documented in the literature, only a very brief description of each is given herein followed by some references related to it.

\subsection{Concurrent engineering}

The term concurrent engineering (CE) was coined in 1986 by the Institute for Defense Analysis (IDA) Report R-338: "Concurrent engineering is a systematic approach to the integrated, concurrent design of products and their related processes, including manufacture and support. This approach is intended to cause the developers, from the outset, to consider all elements of the product life cycle from concept through disposal, including quality, cost, schedule, and user requirements." (IDA, 1986, p. v).

\subsection{System engineering}

The IEEE-Std 1220-1994 states the following definition of systems engineering: "[...] an interdisciplinary collaborative approach to derive, evolve, and verify a life cycle balanced system solution that satisfies customer expectations and meets public acceptability". (IEEE, 1994, p. 4). It also defines two other terms to support its definition of systems engineering which are adopted by this work:

- Life cycle: the system or product evolution initiated by a user need or by a perceived customer need through the disposal of consumer products and by-products.
- Customer: a person or organization ordering, purchasing, receiving, or affected by a product or process. Customers include developers, manufacturers, testers, distributors, operators, supporters, trainers, disposers, and the general public.

\subsection{Integrated product development}

Loureiro (1999) defines integrated development as a product development approach for the integrated and concurrent development of a product, its life cycle processes and their performing organizations. It takes into consideration, from the outset, life cycle process and organization requirements which, together with the product specific requirements, drive the product development process. Integration of product, life cycle process and organization takes place by recognizing that their attributes affect each other and that a balanced solution that satisfies stakeholder requirements cannot be achieved without consideration of the relationships among those attributes.

\subsection{Technology assessment}

As Poter and Weisbecker point out (1993, p. 13):

Technology assessment ultimately comprises a systems approach to the management of technology reaching beyond technology and industrial aspects into society and environmental domains. Initially, it deals with assessment of effects, consequences and risks of a technology, but also is a forecasting function looking into the projection of opportunities and skill development as an input to strategic planning.

\subsection{Technology forecasting}

Coates et al. (2001) defines it as a purposeful and systematic attempt to anticipate the potential direction, rate, characteristics and effects of technological change, especially invention, innovation, adoption, and use. Balaguer (2005, p. 21), by its turn, defines technology forecasting in a broad way as "[...] a process that looks to the future and the results of this process, which anticipate, extrapolate or forecast capacities, applications and functionalities of machines, process and techniques.[...] the process outcomes, expressed in words or numbers, are showed in a useful way to the decision and policy makers, consequently increasing their state of alert about future's threats and opportunities."

\subsection{Technology description}

It is a subset of technology forecasting, according to Walsh (2001). It aims at reducing a technology to as few and as simple a set of words as possible. The goal of technology description is to enable a competent individual to quickly grasp the form and value of a technology with which they 
are unfamiliar with.In this sense, technology description process helps to distill the essence of an emerging new technology into a few sentences that most people can understand. It emerges as a powerful tool to allow one to simply express what a technology is about. It consists of a series of questions that serve as a minimum guideline of what needs to be known to understand a technology.

\subsection{Technology monitoring and technology scouting}

Paap (2006) has systematized and amplified the monitoring aspect to a Technology Scouting focused on innovation perspective. Technology Scouting is defined as an organized approach to looking externally for technology that can be adapted to meet the tactical or strategic development needs of an organization. In this way, technology scouting provides a link between the organization (internal) and the environmental (external).

\subsection{Monte Carlo technique and simulation}

Wittwer (2004) states the Monte Carlo is an accurate probabilistic technique to simulate reality, or uncertainty, by randomly generating values within a pre-specified range. It is a technique for analyzing uncertainty propagation, where the goal is to determine how random variation, lack of knowledge or error affect the sensitivity, performance or reliability of a system that is being modeled.

\section{AT2IPD - Assessing Technology Infusion Impact on Product Development}

The method proposed herein addresses the necessity of bringing and dealing with information about the impact of technology infusion to the early phases of the aircraft design, taking into account the product life-cycle and the stakeholders' needs, in order to provide a better decision making on which technologies to use. The AT2IPD is as seven-step method depicted in Figure 1.

The steps are:

Step 1 - Define the Problem

Step 2 - Establish Product Baseline

Step 3 - Model Metrics

Step 4 - Simulate Metrics of Product Baseline

Step 5 - Identify and Characterize Technology(ies)

Step 6-Determine Technology Impact, Applicability and Uncertainty on Metrics

Step 7 - Determine Technology Impact on Product

The goal of the method is to provide a framework where technologies could be assessed to determine its impact when infused in an aeronautical product. Each step of the AT2IPD is detailed as follows.

\subsection{Step 1 - define the problem}

The first step is to define the problem to be analyzed. In order to formulate the problem, a stakeholder need must exist or a request for proposal must be stated to drive the design of a product and the identification of technology that might be infused into the product. The definition of the stakeholders' requirements must capture the needs of the airframe and engine manufacturer, airlines, airports, passengers, and society as a whole through operational and environmental regulations. The requirements must be mapped into some economic, engineering or mathematically quantifiable terminology.

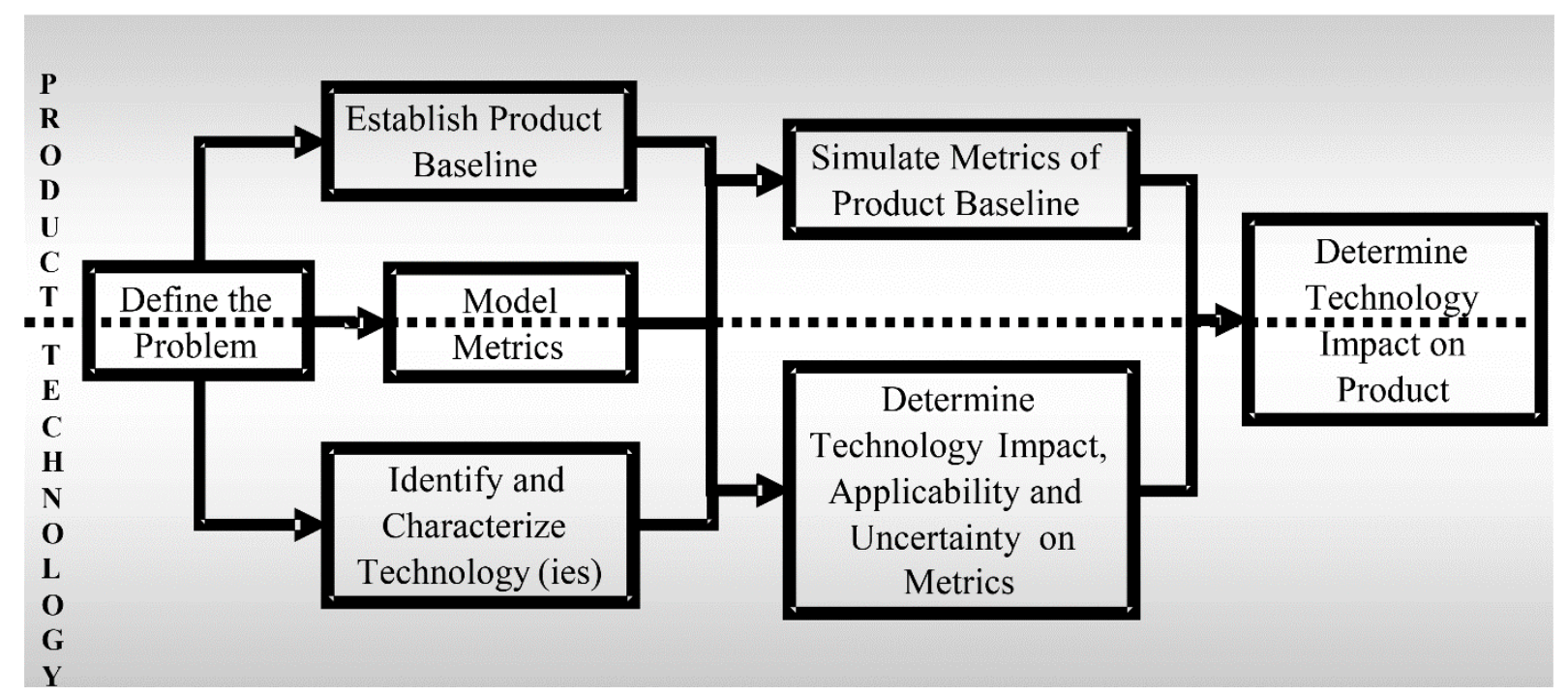

Figure 1. Process to Assess the Impact of Technology Infusion in Aeronautical Products. 
At this step, the needs may be objectives or constraints and they must be translated into system metrics, or a system attribute that is tracked for the purpose of decision making. The system metrics are the thresholds of the system under analysis can be measured with.

\subsection{Step 2 - establish product baseline}

Once defined the problem in terms of system metrics, objectives, constraints and evaluation criteria the next step aims at defining a product baseline.

Initially, the experience, knowledge and intuition of the designer are used to identify potential solutions to meet the customer requirements. In general, a concept - the Product Baseline - is established to begin the feasibility investigation. At this point, it is expected that conventional or existing technologies are chosen in order to minimize investment costs and program risks.

It is important to emphasize that the Product Baseline could be either a proposed new design or an existing product.

\subsection{Step 3 - model metrics}

A fundamental requirement for any decision making process is the ability to quantitatively assess the customer requirements that drive a design. This can be achieved through Modeling and Simulation.

Thus, this step aims to translate the stakeholders' requirements defined in Step 1 into quantifiable engineering parameters. These, by their turn, are affected by the Product Baseline and by Technologies under investigation.

An important aspect to be taken into consideration at this point is the level of fidelity of the model, which means how good and sophisticated isor has to be the models in order to better represent the real product, and it is dependable of the desirable results and its accuracy.

\subsection{Step 4 - simulate metrics of product baseline}

Once the stakeholders' requirementswere translated into system metrics (step 1), the system metrics were modeled into quantifiable engineering parameters (step 3), and a product baseline established (step 2); step four consistsof establishing datum values for all customer requirements (system metrics) based on the characteristic and attributes defined at the product baseline.

The output of this step is the values of the system metrics for the product baseline. Those values are supposed to be changed with the infusion of new technologies.

\subsection{Step 5 - identify and characterize technology(ies)}

Based on the problem defined in terms of system metrics, objectives, constraints and evaluation criteria, the current step aims to look for technology that could address one or more objectives or constrains affecting the system metrics.
For this purpose, one might use the approach of technology monitoring and technology scouting described in Section 2. Once identified some possible technology(ies) that address the defined problem, it is necessary to characterize it (them). To do so, the use of the technology description approach also described in the Section 2 might help.

Whenever several technologies have been identified and characterized, it is necessary to establish and formalize physical compatibility rules among them. The purpose of this is to eliminate combinations that are not feasible. Incompatibilities arise when technologies are competing for the same application or one technology severely degrades the intended function or integrity of the other.

\subsection{Step 6 - determine technology impact, applicability and uncertainty on metrics}

At this point, it is necessary to identify where the technology under evaluation has impact on the quantifiable engineering parameters modeled in Step 3 and also to indicate how much is this impact in terms numerical values.

The impact that each technology has on the metrics may originate from three sources: expert team questionnaires, physics-based modeling or literature reviews.

It is also part of the activities of this step to determine where and how much the technology is applicable on aeronautical products. Then the uncertainty associated to the chosen technology has to be evaluated. It is worth mentioning that each source of impact and applicability estimation has an associated uncertainty.

In order to evaluate the uncertainty, the TRL definition (MANKINS, 1995) might be used as aguide. Despite the fact that TRL description is basically qualitative, it is expected to have more uncertainty when the technology is at lower levels of TRL.

\subsection{Step 7 - determine technology impact on product}

Finally, the technologies aresimulated to be applied to the product baseline and thus evaluated. The simulation is made by applying the data of modified metrics (Step 6) into the datum values of the product baseline (Step 4) at the modeled system metrics (Step 3).

The evaluation of the technologies considered for infusion provides data and information to the decision-maker and it can be performed from two view points:deterministic or probabilistic.

At the deterministic perspective, the evaluation is made simulating the modified metrics by the technology impact and applicability, not take into account the uncertainty values. Doing so, the result is the effect of technology infusion on product through the modification of the system metrics at the product level. The deterministic perspective 
is useful to get a rapid assessment of the potential impact of the technology at the product not taking into account how likely is to get at this impact, and so, provide to the decision-maker information to narrow-down the amount of technologies and their combination for further investigation.

The evaluation of a single technology or a combination of technologies from the probabilistic perspective is similar to that of the deterministic, except that the technology impact and applicability are probabilistic distributions rather than single point values. To quantify the impact, a Monte Carlo Simulation is performed on the simulated metrics of the product baseline (Step4), modified by the values and uncertainty as established in Step 6.The probabilistic evaluation provides a more realistic assessment of the uncertainty and risk associated with the impact of immature technologies.

\section{Case usage and analysis}

The AT2IPD method is applied to evaluate infusion of three technologies and their combination in an existing airplane, considering a scenario of replacement or improvement of this product in the next 10-15 years. It has been used both, deterministic and probabilistic perspectives. The objective of this theoretical case analysisis to show the feasibility of the proposed method.

\subsection{Step 1 - define the problem}

Boeing B737 family and Airbus A320 family are worldwide recognized successful aircraft products in the segment of single aisle, narrow body commercial passenger jet aircraft, with capacity of around 150 passengers and range of about $5700 \mathrm{~km}$. Boeing and Airbus together have a fleet of more than 9000 aircrafts delivered to airlines worldwide.

Despite the latest movements of both companies to reengine their product (BOEING, 2011; FLIGHTGLOBAL, 2010), the family lifespan were extended by something like 10 year; so, it is expected an all new family of narrow body aircraft by the end of next decade, 2030. The all new design should incorporate several technology advancesin power plants, materials, aerodynamics and flight decks, in order to promote another double digit improvement as well as lead to a product that meet the requirements of the scenario pointed out at Section 1.

An important aspect to be taken into account in the new aeronautical product is the structural efficiency of the airframe in terms of weight and cost of material. Reducing structural weight could result in a single or combined of the following effects: less fuel consumption, more paid load and more range. Material cost reduction leads to reduction in acquisition cost of the aircraft. All these represent important marketing and sales aspects for the aircraft manufacturers.

Problem Definition: Reduce airframe weight and cost of material for the aircraft segment of a single aisle, narrow body commercial passenger jet aircraft, with capacity of around 150 passengers and range of about $3000 \mathrm{~nm}$ $(5700 \mathrm{~km})$. The targets are: $5 \%$ reduction of the aircraft empty weight and $2.5 \%$ reduction of material cost, taking as baseline, the current aircraft in operation, B737 and A320.

\subsection{Step 2 - establish product baseline}

The product baseline is assumed to be the similar to the A320. Table 1 shows the A320 characteristics, where the product baseline characteristics are taken from.(Airbus, 2014; Airbus, 2015)

\subsection{Step 3 - model metrics}

The two metrics to be modeled at this case are: weight, focused on structural weight and material cost.

\subsubsection{Weight modeling}

The following equations (RAIMER, 1999) represent the weight breakdown:

Table 1. Product Baseline Characteristics.

\begin{tabular}{|c|c|c|c|c|c|}
\hline \multicolumn{2}{|c|}{ Aircraft Dimension } & \multicolumn{2}{|c|}{ Basic Operating Data } & \multicolumn{2}{|c|}{ Design Weights } \\
\hline Characteristics & Values & Characteristics & Values & Characteristics & Values \\
\hline Overall length & $37.57 \mathrm{~m}$ & Engines & $\begin{array}{l}\text { two CFM56-5 or } \\
\text { IAE V2500 }\end{array}$ & Max. takeoff weight & 73.5 tons \\
\hline Height & $11.76 \mathrm{~m}$ & Engine thrust range & $111-120 \mathrm{kN}$ & Max. landing weight & 64.5 tons \\
\hline Fuselage diameter & $3.95 \mathrm{~m}$ & $\begin{array}{l}\text { Typical passenger } \\
\text { seating }\end{array}$ & 150 & $\begin{array}{c}\text { Max. zero fuel } \\
\text { weight }\end{array}$ & 61.0 tons \\
\hline Wingspan (geometric) & $34.10 \mathrm{~m}$ & $\begin{array}{c}\text { Range } \\
\text { (w/max. passengers) }\end{array}$ & $4,800(5,700) \mathrm{km}$ & Max. fuel capacity & 23,8601 \\
\hline Wing area (reference) & $122.6 \mathrm{~m} 2$ & $\begin{array}{c}\text { Max. Operating } \\
\text { Mach number }\end{array}$ & $0.82 \mathrm{Mo}$ & $\begin{array}{l}\text { Typical operating } \\
\text { weight empty }\end{array}$ & 42.4 tons \\
\hline $\begin{array}{l}\text { Wing sweep } \\
(25 \% \text { chord })\end{array}$ & $25 \mathrm{deg}$ & $\begin{array}{l}\text { Bulk hold volume - } \\
\text { Standard/option }\end{array}$ & $37.41 \mathrm{~m} 3$ & $\begin{array}{c}\text { Typical volumetric } \\
\text { payload }\end{array}$ & 16.6 tons \\
\hline
\end{tabular}

Note: As there is a growing tendency of using of composite materials in structural aircraft application, the weight of the product baseline is halved in composite and metallic. 


$$
\begin{aligned}
& W_{\text {TOGW }}=W_{\text {crew }}+W_{\text {payload }}+W_{\text {fuel }}+W_{\text {empty }} \\
& W_{\text {empty }}=W_{\text {Structure }}+W_{\text {System }} \\
& W_{\text {Structure }}=\sum_{i} W_{i}
\end{aligned}
$$

\subsubsection{Material cost modeling}

The following equation represents the material cost model:

$$
\$ M=\sum_{i} \frac{\$ R M_{i} \cdot W_{i}}{\left(\frac{W_{\text {final_part }}}{W_{R M}}\right)_{i}} \begin{aligned}
& \text { the i-index represents } \\
& \text { different material type }
\end{aligned}
$$

As the purpose of the method is to be used at the preliminary design phases, there is no need for high fidelity models; thus all the values to be used in the method can be taken as medium values.

\subsection{Step 4 - simulate metrics of product baseline}

The characteristic and attributes defined at the product baseline has to be translated in terms of the parameters established at the step 3 .

\subsubsection{Weight metrics}

It is assumed that:

$$
W_{\text {TOGW }}=73,500 \mathrm{~kg}, \text { as indicated in Table } 1
$$

For this type of aircraft (RAIMER, 1999; Airbus, 2015; Airbus, 2014):

$$
\begin{aligned}
& W_{\text {empty }}=0,47 \cdot W_{\text {TOGW }}=34,545 \mathrm{~kg} \\
& W_{\text {Structure }}=W_{\text {System }}=0,5 \cdot W_{\text {empty }}=17,273 \mathrm{~kg}
\end{aligned}
$$

As defined at step 2,

$$
W_{\text {Composite }}=W_{\text {Metallic }}=0,5 \cdot W_{\text {Structure }}=8,636 \mathrm{~kg}
$$

\subsubsection{Material cost metrics}

The medium cost of composite raw material per weight were determined taking into account the amount of resin and fiber used in a typical structural and the information of raw material cost (HEXCEL, 2015).

At the same way, the medium cost of metallic raw material per weight were determined similarly to the typical use of aluminum, titanium and steel in aircraft structure and the information of raw material cost (ALCOA, 2015).

The values are shown in Table 2 .

Based on Equation 2, it can be written:

$$
\$ M=\sum_{i} \frac{\$ R M_{i} \cdot W_{i}}{\left(\frac{W_{\text {final_part }}}{W_{R M}}\right)_{i}} \cong U S D 2.7 \text { million per aircraft }
$$

\subsection{Step 5 - identify and characterize technology(ies)}

In order to carry out the Steps 5 and 6 , technical specialists were consulted, to obtain the characteristics of the technology and quantify their impact.

Regarding to technologies with potential to be infused into the product and impact aircraft structure weight and cost, three of them were identify, based on the trends and evolution in terms of metallic and composite materials, and characterized:

\subsubsection{T1: Composite with Carbon Nanotubes (CNT)}

Composite with CNT could be described as advanced composite materials where there were added CNT at the resin or to the fibers. This technology is presenting better mechanical and electrical proprieties when compared with the traditional composite material. Currently, it is a low maturity technology, which implies in higher costs.In terms of applicability of the technology at aircraft structures, it is possible to use in all of the components made by traditional composite material. It is expected that the amount of CNT utilized to produce a structural part will be less than $0.05 \%$ of the component weight.

\subsubsection{T2: Near Net Shape Metallic}

Near Net Shape Metallic could be described as metallic parts produced with shape closer to the shape of the final part shape. Forged and Investment Casting made parts are examples of technologies that belong to this group.This technology proposes to increase the ratio of the finished part weight and raw material weight needed to produce this part. It is expected to increase the cost of raw material with this technology. Improvements on mechanical properties

Table 2. Material Cost Metrics for Product Baseline.

\begin{tabular}{|c|c|c|}
\hline \multirow{2}{*}{ Metrics } & \multicolumn{2}{|c|}{ Material Characteristics } \\
\cline { 2 - 3 } & Metallic & Composite \\
\hline$\$ R M$ & USD 9/ kg raw material & USD 80/ kg raw material \\
\hline$W_{\text {final_part }} / W_{R M}$ & $8 \%$ & $40 \%$ \\
\hline
\end{tabular}


of the part are not expected to be of great impact.In terms of applicability, this technology is well applicable in components with highly complex geometry.

\subsubsection{T3: Advanced Aluminum and Titanium Alloys}

Advanced Aluminum and Titanium Alloys are alloys compounded by not usual metallic elements like Lithium and Magnesium, for e.g. Al- $\mathrm{Li}, \mathrm{Al}-\mathrm{Mg}$, Ti622.This technology intends to provide a better strength to weight ratio; it is likely to be applied in components made by traditional metallic material.

Once identified and characterized the technologies, Table 3 establishes and formalizes physical compatibility rules among the technologies themselves and between the product baseline and the technologies, presented in a Compatibility Matrix. In this caseanalysis, all the technologies are compatible with each other and could be infused at the product baseline, as Table 3 shows.

\subsection{Step 6 - determine technology impact, applicability and uncertainty on metrics}

Based on Equations 1 and 2, Table 4 shows the parameters which are likely to be modified by the technologies as well as the effect of the technologies upon them. Table 5 and 6 present, respectively, the applicability of the technologies on the product and the uncertainty model and values on metrics.

\subsection{Step 7 - determine technology impact on product}

Finally, the application of the named technologies to the product baseline can be simulated and their impact evaluated. Table 7 points out the metrics variation by each group of technology infusion, in both perspectives, deterministic and probabilistic (note: for the probabilistic evaluation, a Monte Carlo Simulation was performed for 5000 cases).

The results in both perspectives, deterministic or probabilistic, allow one to assess the benefits and penalties which yield from technology infusion at the product level. From this caseanalysis, it can be stated that none of the technologies or their combinations could meet the both reduction targets of 5\% in aircraft empty weight and $2.5 \%$ in material cost.

It is possible to make a risk assessment by exploring the results of probabilistic perspective. This is based on how likely the technology is able to meet the targets, based on the cumulative frequency as shown in Figure 2.

Based on the cumulative frequency results, all technologies and combination of technologies simulated have less than $60 \%$ chance of fulfill the empty weight target;

Table 3. Compatibility Matrix.

\begin{tabular}{|c|c|c|c|c|}
\hline & Baseline & T1 & T2 & 1 \\
\hline Baseline & & 1 & 1 & 1 \\
\hline T1 & 1 & & 1 & 1 \\
\hline T2 & 1 & 1 & 1 & \\
\hline
\end{tabular}

$1 \rightarrow$ compatible. $0 \rightarrow$ not compatible.

Table 4. Technology Impact.

\begin{tabular}{|l|c|c|c|}
\hline \multirow{2}{*}{ Parameter } & T1 & Tariation (\%) & T2 \\
\cline { 2 - 4 } & $-20 \%$ & $0 \%$ & $0 \%$ \\
\hline$W_{\text {Composite }}$ & $0 \%$ & $0 \%$ & $-5 \%$ \\
\hline$W_{\text {Systallic }}$ & $0 \%$ & $0 \%$ & $0 \%$ \\
\hline$\$ R M_{\text {Composite }}$ & $40 \%$ & $0 \%$ & $0 \%$ \\
\hline$\$ R M_{\text {Metallic }}$ & $0 \%$ & $10 \%$ & $20 \%$ \\
\hline$\left(W_{\text {final_part }} / W_{R M}\right)_{\text {Composite }}$ & $0 \%$ & $0 \%$ & $0 \%$ \\
\hline$\left(W_{\text {final_part }} / W_{R M}\right)_{\text {Metallic }}$ & $0 \%$ & $50 \%$ & $0 \%$ \\
\hline
\end{tabular}

Table 5. Technology Applicability.

\begin{tabular}{|l|c|c|c|}
\hline \multirow{2}{*}{ Components } & \multicolumn{3}{c|}{ Applicability (\%) } \\
\cline { 2 - 4 } & T1 & T2 & T3 \\
\hline Composite & $100 \%$ & $0 \%$ & $0 \%$ \\
\hline Metallic & $0 \%$ & $40 \%$ & $100 \%$ \\
\hline System & $0 \%$ & $0 \%$ & $0 \%$ \\
\hline
\end{tabular}


Table 6. Uncertainty Evaluation.

\begin{tabular}{|c|c|c|c|}
\hline \multirow{2}{*}{ Parameter } & \multicolumn{3}{|c|}{ Uncertainty Model and Values } \\
\hline & T1 & $\mathrm{T} 2$ & T3 \\
\hline$W_{\text {Composite }}$ & $\begin{array}{c}\text { Normal Distribution } \\
\text { (Mean: }-20 \% \text {; St. Dev.: 20\%) }\end{array}$ & -- & -- \\
\hline$W_{\text {Metallic }}$ & -- & $\begin{array}{c}\text { Normal Distribution } \\
\text { (Mean: } 0 \% \text {; St. Dev.: 1\%) }\end{array}$ & $\begin{array}{c}\text { Normal Distribution } \\
\text { (Mean: }-5 \% \text {; St. Dev.: } 20 \% \text { ) }\end{array}$ \\
\hline$W_{\text {System }}$ & $\begin{array}{l}\text { Normal Distribution } \\
\text { (Mean: } 0 \% \text {; St. Dev.: } 5 \% \text { ) }\end{array}$ & -- & -- \\
\hline$\$ R M_{\text {Composite }}$ & $\begin{array}{c}\text { Normal Distribution } \\
\text { (Mean: } 40 \% \text {; St. Dev.: } 20 \% \text { ) }\end{array}$ & -- & -- \\
\hline$\$ R M_{\text {Metallic }}$ & -- & $\begin{array}{c}\text { Normal Distribution } \\
\text { (Mean: } 10 \% \text {; St. Dev.: } 10 \% \text { ) }\end{array}$ & $\begin{array}{c}\text { Normal Distribution } \\
\text { (Mean: } 20 \% \text {; St. Dev.: } 20 \% \text { ) }\end{array}$ \\
\hline$\left(W_{\text {final part }} / W_{R M}\right)_{\text {Composite }}$ & -- & -- & -- \\
\hline$\left(W_{\text {final_part }} / W_{R M}\right)_{\text {Metallic }}$ & -- & $\begin{array}{c}\text { Normal Distribution } \\
\text { (Mean: } 50 \% \text {; St. Dev.: } 20 \% \text { ) }\end{array}$ & -- \\
\hline Composite Applicability & $\begin{array}{c}\text { Triangular Distribution (Low: } \\
\text { 95\%; High: } 100 \% \text {; Moda: } 100 \% \text { ) }\end{array}$ & -- & -- \\
\hline Metallic Applicability & -- & $\begin{array}{l}\text { Triangular Distribution (Low: } \\
\text { 20\%; High: } 60 \% \text {; Moda: } 40 \% \text { ) }\end{array}$ & $\begin{array}{l}\text { Triangular Distribution (Low: } \\
\text { 95\%; High: 100\%; Moda: 100\%) }\end{array}$ \\
\hline System Applicability & $\begin{array}{c}\text { Triangular Distribution (Low: } \\
0 \% \text {; High: } 1 \% \text {; Moda: } 0 \% \text { ) }\end{array}$ & -- & -- \\
\hline
\end{tabular}

Table 7. Technology Impact.

\begin{tabular}{|c|c|c|c|c|c|c|}
\hline \multirow{3}{*}{ Technology } & \multicolumn{3}{|c|}{$W_{\text {empty }}$} & \multicolumn{3}{|c|}{$\$ M$} \\
\hline & \multirow{2}{*}{ Deterministic } & \multicolumn{2}{|c|}{ Probabilistic } & \multirow{2}{*}{ Deterministic } & \multicolumn{2}{|c|}{ Probabilistic } \\
\hline & & Mean & Std. Dev. & & Mean & Std. Dev. \\
\hline $\mathrm{T} 1$ & $-5.00 \%$ & $-4.87 \%$ & $4.95 \%$ & $7.68 \%$ & $7.80 \%$ & $20.47 \%$ \\
\hline $\mathrm{T} 2$ & $0.00 \%$ & $0.00 \%$ & $0.10 \%$ & $-4.80 \%$ & $-4.68 \%$ & $2.60 \%$ \\
\hline T3 & $-1.25 \%$ & $-1.27 \%$ & $4.87 \%$ & $5.04 \%$ & $4.75 \%$ & $10.82 \%$ \\
\hline$(\mathrm{T} 1+\mathrm{T} 2)$ & $-5.00 \%$ & $-4.79 \%$ & $4.87 \%$ & $5.55 \%$ & $5.55 \%$ & $20.15 \%$ \\
\hline (T1+T3) & $-6.25 \%$ & $-6.05 \%$ & $6.89 \%$ & $12.72 \%$ & $12.43 \%$ & $22.72 \%$ \\
\hline$(\mathrm{T} 2+\mathrm{T} 3)$ & $-1.25 \%$ & $-1.28 \%$ & $4.87 \%$ & $-0.66 \%$ & $-0.77 \%$ & $9.70 \%$ \\
\hline$(\mathrm{T} 1+\mathrm{T} 2+\mathrm{T} 3)$ & $-6.25 \%$ & $-6.07 \%$ & $6.94 \%$ & $7.02 \%$ & $6.98 \%$ & $22.36 \%$ \\
\hline
\end{tabular}
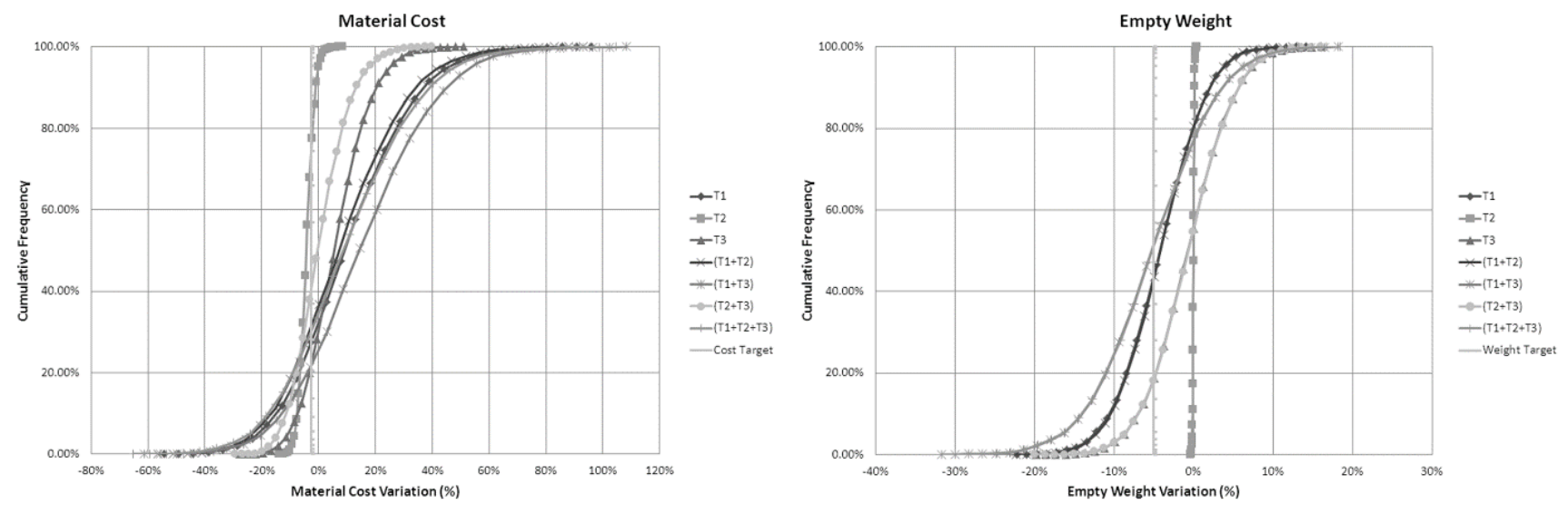

Figure 2. Cumulative Frequency of Technology Impact on Metrics. 
with regards to the material cost target, only the Near Net Shape Metallic technology (T2) has more than 50\% chance to fulfill the target.

\section{Conclusion}

This paper has described a method for assessing the impact of technology infusion in aeronautical productsin the presence of technological uncertainty. The seven-step procedure was detailed as follows: problem formulation, product baseline establishment, system metrics modeling, simulation the system metrics with the product baseline, identification and characterization of technologies to be infused, determination of the technology impact at the metrics, applicability and compatibility on product, and determination of technology impact at product metrics level.

Overall, the primary benefits gained from this new approach are the ability to bring and deal with information about one or more technologies, product and requirements (system metrics) in order to assess the benefits, penalties and risks at the product level, taking into account the product life-cycle and the stakeholders' needs.

The feasibility of the method was demonstrated through an example problem involving the investigation of effects of infusing up to three aircraft structure technologies on system metrics of structural weight and material costfor the aircraft segment of a single aisle, narrow boy commercial passenger jet aircraftaccounting for benefits, penalties and risk assessment.

The results shows that none of the technologies or their combinations could meet the both reduction targets of $5 \%$ in aircraft empty weight and $2.5 \%$ in material cost; and more, all have less than $60 \%$ chance of fulfill the empty weight target, only the Near Net Shape Metallic technology (T2) has more than $50 \%$ chance to fulfill the material cost target.

Based on the resultsprovided by applying AT2IPD, one could drive its actions on,either, a more depth investigation and understanding of each of the technologies and their combinations in order to review andreduce the uncertainty of the technologies impacts on the metrics, or make a more detailed assessment with more specific model metrics and narrowing down the technologies application into the products, or even selecting other group of technologies, before decide what set of technologies should be part of the product.

\section{Nomenclature}

$$
\begin{aligned}
& W_{\text {TOGW }}=\text { takeoff gross weight } \\
& W_{\text {crew }}=\text { crew weight } \\
& W_{\text {payload }}=\text { payload or passenger weight } \\
& W_{\text {fuel }}=\text { fuel weight } \\
& W_{\text {empty }}=\text { empty weight which includes aircraft } \\
& \text { structure and systems }
\end{aligned}
$$

$W_{\text {structure }}=$ weight of aircraft structure, which includes wing, fuselage, stabilizers and others

$W_{\text {system }}=$ weight of aircraft system, including avionics, engines, landing gear, interiors and others

$W_{i}=$ total weight of the structural parts made of material type "i"

$\$ M=$ material cost at the final part of the structure

$\$ R M=$ cost of the raw material per weight

$W_{\text {final_par }} / W_{R M}=$ rate of final part weight and raw material weight spend to produce this part;it gives a measure of the utilization of the material by the manufacturing process applied

\section{References}

Airbus. Airbus A320. 2015. Available from: <http://www. airbus.com/aircraftfamilies/passengeraircraft/a320family/ a320/>. Access in: 15 May 2015.

Airbus. Airbus family figures. 2014. Available from: $<$ http://www.airbus.com/fileadmin/media_gallery/files/ brochures_publications/aircraft_families/Airbus-FamilyFigures-July2014.pdf $>$. Access in: 15 May 2015.

ALCOA. Alcoa aerospace products. 2015. Available from: $<$ http://www.alcoa.com/aerospace/en/products/overview. asp>. Access in: 14 Mar 2015.

BAKER, A. P. The role of mission requirements, vehicle attributes, technologies and uncertainty in rotorcraft system design. 2002. Tese-Georgia Institute of Technology, Geórgia, Atlanta, 2002.

BALAGUER, D. L. E o futuro, de que é feito afinal? Acerca de uma hipótese sobre a natureza do futuro e de uma proposta para prospectiva tecnológica. 2005. Dissertação-Instituto Tecnológico de Aeronáutica, São José dos Campos, 2005.

BOEING. Boeing introduces 737 MAX with launch of new aircraft family. 2011. Available from: <http://boeing. mediaroom.com/2011-08-30-Boeing-Introduces-737-

MAX-With-Launch-of-New-Aircraft-Family>. Access in: 30 May 2015.

COATES, V. et al. On the future of technological forecasting. Technological Forecasting and Social Change, v. 67 , n. 1, p. 1-17, 2001. http://dx.doi.org/10.1016/S00401625(00)00122-0.

Flight Global. Airbus A320neo to enter service in 2016. 2010. Available from: <http:/www.flightglobal.com/news/ articles/airbus-a320neo-to-enter-service-in-2016-350357/>. Access in: 30 May 2015.

HEXCEL. Hexcel products. 2015. Available from: <http:// www.hexcel.com/products/>. Access in: 14 May 2015. 
IEEE. IEEE 1220-1994: Trial-use standard for application and management of the systems engineering process. New York, USA: Institute of Electrical and Electronics Engineers, 1995.

Institute of Defense Analysis - IDA. Report R-338. Washington: GPO, Dec 1986.

LOUREIRO, G. A systems engineering and concurrent engineering framework for the integrated development of complex products. 1999. Tese-Department of Manufacturing Engineering, Loughborough University, 1999.

MANKINS, J. C. Technology readiness levels. Washington, DC: Advanced Concepts Office, Office of Space Access and Technology, NASA, 1995. White Paper.

PAAP, J. Technology scouting to accelerate innovation. In: A MANAGEMENT ROUNDTABLE EXECUTIVE
WORKSHOP, 2006, Cambridge MA. Proceedings... Management Roundtable, 2006.

POTER, A. L.; WEISBECKER, L. W. Issues in performing technology assessment for development. Paris: UN Expert Group Meeting on Technology Assessment, Monitoring and Forecasting, 1993.

RAIMER, D. P. Aircraft design: a conceptual approach. 3 ed. Reston, Va: American Institute of Aeronautics and Astronautics, 1999. (AIAA Education Series).

WALSH, S. Technological forecasting and assessment. New Delhi: Technology Information, Forecasting, Assessment Council (TIFAC), 2001.

WITTWER, J. W. Monte Carlo simulation basics. 2004. Albuquerque: Vertex42. Available from: <http://www. vertex42.com/ExcelArticles/mc/MonteCarloSimulation. html>. Access in: 15 May, 2015. 